\title{
Concepts and contexts in engineering and technology education: an international and interdisciplinary Delphi study
}

\author{
Ammeret Rossouw • Michael Hacker • Marc J. de Vries
}

Published online: 2 July 2010

(C) The Author(s) 2010. This article is published with open access at Springerlink.com

\begin{abstract}
Inspired by a similar study by Osborne et al. we have conducted a Delphi study among experts to identify key concepts to be taught in engineering and technology education and relevant and meaningful contexts through which these concepts can be taught and learnt. By submitting the outcomes of the Delphi study to a panel of experts in a twoday meeting we were able to add structure to the Delphi results. Thus we reached a concise list of concepts and contexts that can be used to develop curricula for education about engineering and technology as a contribution to technological literacy goals in education.
\end{abstract}

Keywords Delphi study - Engineering and technology education - Concept-context . Expert panel · Engineering and technology education curriculum development .

Technological literacy $\cdot$ ETE $\cdot$ Teaching concepts in contexts

\section{Introduction}

One of the main issues in the development of engineering and technology education is the search for a sound conceptual basis for the curriculum. This search has become relevant as the nature of technology education has changed: it has gradually evolved from focusing on skills to focusing on technological literacy. This literacy implies that pupils and students have developed a realistic image of engineering and technology. What is a realistic image of engineering and technology? The answer is derived from several sources; among them are the academic disciplines that study the nature of engineering and technology, such as the philosophy of technology, the history and sociology of technology, and design methodology (see De Vries 2005 for an extensive description of the insights that these disciplines have brought forward for technology education). A different approach is to ask

A. Rossouw $(\square) \cdot$ M. J. de Vries

Delft University of Technology, Delft, The Netherlands

e-mail: ammeret@rossouw.eu

M. Hacker

Hofstra University, Hempstead, USA 
experts for their opinions on this matter, and that is the route we have taken to find broad concepts that offer a basis for developing engineering and technology education.

We need to be explicit about what we mean by engineering and technology. Technology, the broader of the two disciplines, encompasses the way humans develop, realize, and use (and evaluate) all sorts of artifacts, systems, and processes to improve the quality of life. Technological literacy is what people need to live in, and control, the technological environment that surrounds us. This literacy comprises practical knowledge, reasoning skills, and attitudes. Engineering is more limited. It encompasses the professions that are concerned with the development and realization of such artifacts, systems, and processes.

Engineering and technology education has long been delivered in two ways: through general education and through vocational education. In general education, the focus historically has been on practical (craft) skills. However, this emphasis has changed in most countries: traditional school subjects have been replaced by what is generally called "technology education." The main purpose of technology education is developing technological literacy, but in some cases a vocational element remains. In vocational education the focus has been on preparing for a career in the commerce or in technical areas. This kind of teaching has focused on specific knowledge and skills. The latest development is that engineering has been accorded a more substantial place in general (technology) education. This shift is combined with the integration of science and math and leads to what is known as science, technology, engineering, and mathematics (STEM) education. Our use of the term engineering and technology education (ETE) relates to these contemporary developments and characterizes ETE as important and valuable for all students. Traditionally, curricula for engineering and technology education are structured according to either engineering disciplines (e.g., mechanical engineering, electrical engineering, construction engineering) or application fields (e.g., transportation, communication). These structures do not offer much insight into the nature of engineering and technology. We believe a better approach for developing insights is to search for basic concepts that are broadly applicable in engineering and technology and cut through different engineering domains and application fields. An example of such a concept is the systems concept. In the 1970s, the Man-Made World (David et al. 1971) project focused on developing a curriculum based on such concepts. Since then, little work has been done in this area, although useful work has been done on identifying usable concepts.

The various efforts to develop a sound conceptual basis for teaching engineering and technology have led to the development of important insights and ideas. A major accomplishment was the development of the Standards for Technological Literacy in the USA (International Technology Education Association 2000). In these standards there are many concepts related to engineering and technology. Although eminently useful as focal points for learning, standards typically define what students should know and be able to do in specific content or programmatic areas. In some cases, competencies defined by standards are quite broad; in other cases, the competencies are atomistic.

To enhance standards-driven curricula by helping learners understand relationships among technological domains, this study has identified a set of overarching, unifying concepts that cut across domains and thus give insight into the holistic nature of engineering and technology. These broad, unifying concepts can be used to develop curriculum and learning experiences in engineering and technology education. Some opportunities exist to make this study different from previous ones. We will mention three of the study's components in particular:

(1) We have consulted experts from a variety of disciplines concerned with basic concepts related to engineering and technology. The disciplines are 
- technology education (as a component of general education at the secondary level as well as technology teacher education and educational research);

- engineering education (at the tertiary level) and engineering organizations; philosophy and history of technology;

- design methodology;

- science and technology communication.

This last discipline is concerned with communicating about science, engineering, and technology, and it too is faced with the need to work with clear and broadly applicable concepts related to engineering and technology. We realized that the purpose of this study was to give directions for secondary school education and for that reason we selected a majority of technology educators as they are in the best position to judge what fits with the nature of this level of education. At the same time we strived for a good number of other experts so that their opinion would have sufficient weight in the statistics to disturb a consensus that would otherwise only be based on the technology educators' preferences.

(2) We have consulted experts from a variety of countries. The Standards for Technological Literacy project was primarily an effort involving experts in the US.

(3) We have asked not only for concepts but also for contexts in which the concepts can be taught. This should be seen against the background of recent developments in educational research. Such research has led to the insight that concepts are not learned easily in a top-down approach (i.e., learning the concepts at a general, abstract level first and then applying them to different contexts). Even an approach in which concepts are first learned in a specific context and then transferred to a different context has proved unfruitful (Pilot and Bulte 2006). The most recent insights developed reveal that concepts should be learned in a variety of contexts so that generic insights can grow gradually (Westra et al. 2007). This growth leads to the ability to apply the concepts in new contexts. In this approach, it is important to identify the concepts that should be learned as well as the contexts that are suitable for learning those concepts.

In summary, this article describes a study that has identified basic and broad themes in engineering and technology, as well as the contexts that are suitable for learning about those themes. We have asked an international group of experts (be it with a bias towards the USA) in a variety of disciplines for their input. What we have looked for are overarching concepts and themes that are both basic and broad: they must be transferable over a wide range of engineering and technological fields of study, and subsume and synthesize a body of related sub-concepts. The contexts should be broad enough to provide an understanding of the impact of engineering and technology on society, culture, and the economy, but narrow enough to relate to pupils' and students' own experiences.

\section{Research methodology}

One way to ascertain the opinion of a group of experts is to conduct a Delphi study (Brown 1968; Reeves and Jauch 1978). The reputation of Delphi studies has changed. There was a time when Delphi studies were used frequently However, a growing awareness of the limitations of the Delphi method led to a decline in the method's popularity, evidenced by the fact that fewer Delphi studies were accepted for publication in scholarly journals. Although the number of Delphi studies is still not high, the method has once again been accepted as a serious research design. A Delphi study was conducted by Jonathan Osborne, Sue Collins, Mary Ratcliffe, Robin Millar, and Rick Duschl, a group of well-respected 
science education researchers, and published in a high-quality academic journal, the Journal of Research in Science Teaching, in 2003 (Osborne et al. 2003). This study was relevant not only because it justified our choice of the Delphi method, but also because it had a goal that was very similar to our own: to establish a list of basic and broad concepts related to science for use in the development of science education curricula.

Our research design, similar to the one Osborne et al. used, is typical for Delphi studies. A group of experts were invited by e-mail to participate in the study. In a first round, the 32 experts who agreed to participate were asked to generate concepts (in Osborne et al.'s case for science and in our case for engineering and technology) and rate each one for importance. The number of experts involved is well over the 20-25 usually involved in a Delphi study (Osborne et al. had 23). In our research we have adapted this first round: in addition to asking the experts to generate their own concepts, we provided them with a draft list of concepts to rate on a 1-5 Likert scale. We did this because we wanted to clarify the level of generality we were looking for. In other words, by suggesting such concepts as "systems" and "optimization," we wanted to prevent experts suggesting concepts that were substantially less transferable. As a source of inspiration for such concepts, we used, among others, David et al. (1971), Childress and Rhodes (2008), and Dearing and Daugherty (2004). Another adaptation is that we added draft definitions to the concepts in the draft list. We asked the experts to comment on these and to indicate whether or not they found the defined concepts suitable. The idea here was not to get exact definitions for the concepts, but to make sure everyone was thinking of the same concept when considering its suitability. The following rounds were more standard. In the second and third round the experts were presented with both the new concept entries and our draft list of broad concepts and their amended definitions. We decided not to give back the average scores in the second round, but only in the third round, because we wanted to have the full lists for participants to score, before making the scores public. The experts were asked to give scores of importance again, based on their own opinion and in round three also based on the information related to the total average score of the whole group. No more concepts could be added. We emphasized that our aim was not to reach exact definitions of the concepts. Instead, we hoped to convey the essence of each concept, so that the experts would not need to respond again to the definitions but only rate the concepts. Also, we asked the experts to be sparing with high scores so that only the most important concepts would stand out. We pointed out that aiming for a short list was also the reason why we did not include each concept that the experts had suggested in the first round.

We did something similar for the contexts part, but allowed for more variety in the levels of generality here. In the second and third rounds we therefore included suggestions for contexts of different levels of generality, thereby leaving it to the experts to indicate whether they favored high-level generality contexts or lower-level contexts. In the second round we also mentioned more criteria for ranking the contexts. Usually this second round does not lead to sufficient consensus so a third round is needed. The third round is also needed to check for stability in the answers, for both concepts and contexts. To stimulate consensus in the third round, the experts are asked to account for deviating substantially from the average score. In case this still fails to result in consensus, one can search for subgroups in which consensus can be established (in our case this could, for instance, be the engineering education experts). To make this possible, we have asked the experts to provide some personal background data (age, gender, nationality, educational background, and professional area). The study was conducted during May and July of 2009. In order to stay within the available time, the experts were asked to return their responses in about a week. Several experts were on summer leave, so we have not been able to include all 
responses for every round. For each round, we waited until at least 30 of the 32 experts sent their responses.

This research method, aimed at establishing a consensus of experts' opinions, has both strengths and weaknesses compared to a panel meeting. The main strength is that one can use statistical means to establish whether or not a consensus exists, and this lends certain objectivity to the study (even though the choice for the criteria and critical values for those remains a matter of preference). The main weakness is that one depends totally on opinions rather than facts. This makes the quality of the study dependent on the choice of experts for the Delphi panel. An advantage of a Delphi study over a panel meeting is that no single expert can dominate the consensus. The disadvantage is that it is not possible to discuss the results of the rounds with the experts in a direct interactive way. In our case we have combined the Delphi study and the panel meeting. Thus we hoped to combine the advantages of the Delphi study and the panel meeting.

\section{First phase: the Delphi study}

\section{Data collection}

In the first round, the 32 experts (see Table 1 for the division of experts over the disciplines of philosophy/history of technology, engineering education and technology education) responded to a preliminary list of possible concepts and context by scoring those on a 1-5 scale and adding other concepts and contexts. Besides that they made general comments regarding the set-up of the study and the questionnaire. We will discuss those remarks in the next section, together with the outcomes of the third round.

In the second round, each concept or context that had been proposed by more than one expert was included in the new list of concepts or contexts. To avoid ending up with very long lists of concepts and contexts, we often combined concepts and contexts that were phrased differently but had the same meaning. In some cases we could subsume a suggested concept or context under an already listed concept or context when it was clear that the concept or context was of a lower level of generality than a concept or context that was already in the list. By adding these sub-concepts and sub-contexts we could at the same time give some more substance to the concepts and contexts. A complete account of our decisions in this transition from the first to the second round would require a substantial amount of space and we prefer to refer to the full text of the report that was written for the panel meeting (published on the Internet under the title "CCETE Project. Concepts and contexts in engineering and technology education"). We left it in the second round to the experts to agree or disagree with the decisions we made, using their scores. In the second round the experts could only score the concepts and contexts. This made the transition from the second to the third round an easier transition as we only needed to calculate the statistics for the scores and present those to the experts in the third round. In the third round, we again asked the experts to score, and we also asked them to give a reason for

Table 1 Number of experts

\begin{tabular}{lr}
\hline Philosophy/history and communication of technology & 5 \\
Engineering educator & 7 \\
Technology (Teacher) educator & 20 \\
Total respondents & 32
\end{tabular}


deviating more than 1 point from the average score in case they had a strong individual opinion on a specific concept or context. The aim of this was twofold: we wanted to stimulate experts to search for consensus where possible, and at the same time we wanted to allow for deviating points of view but with motivation so that we could have a discussion about how to appreciate the deviating opinion.

Outcomes after the third round

The results of the third round can be found in Tables 2 and 3.

Table 2 Statistics for the list of concepts

\begin{tabular}{|c|c|c|c|c|c|c|}
\hline Rank & Potential unifying concept/theme & Mean & Mode & SD & $\%$ rating with 4 or 5 & Stability \\
\hline 1 & Design (as a verb) & 4.83 & 5 & 0.38 & 100.0 & 1.2 \\
\hline 2 & System & 4.67 & 5 & 0.48 & 100.0 & 6.1 \\
\hline 3 & Modeling & 4.50 & 5 & 0.57 & 96.7 & 1.9 \\
\hline 4 & Social interaction & 4.26 & 4 & 0.64 & 90.0 & 0.5 \\
\hline 5 & Optimization & 4.00 & 4 & 0.74 & 80.0 & 2.1 \\
\hline 6 & Innovation & 3.85 & 4 & 0.68 & 70.0 & 1.5 \\
\hline 7 & Specifications & 3.85 & 4 & 0.71 & 73.3 & 3.9 \\
\hline 8 & Design (as a noun) & 3.83 & 4 & 0.59 & 70.0 & 2.0 \\
\hline 9 & Sustainability & 3.83 & 4 & 0.59 & 73.3 & 1.4 \\
\hline 10 & Trade-offs & 3.82 & 4 & 0.82 & 70.0 & 2.6 \\
\hline 11 & Energy & 3.79 & 4 & 0.62 & 76.7 & 2.2 \\
\hline 12 & Materials & 3.78 & 4 & 0.74 & 73.3 & 4.0 \\
\hline 13 & Resource & 3.72 & 4 & 0.67 & 73.3 & 0.6 \\
\hline 14 & Technology assessment & 3.76 & 4 & 0.69 & 63.3 & 2.0 \\
\hline 15 & Invention & 3.70 & 4 & 0.73 & 63.3 & 4.6 \\
\hline 16 & Risk and failure & 3.64 & 4 & 0.85 & 60.0 & 1.4 \\
\hline 17 & Information & 3.59 & 4 & 0.74 & 60.0 & 0.4 \\
\hline 18 & Function & 3.54 & 4 & 0.75 & 56.7 & 1.6 \\
\hline 19 & Structure & 3.43 & 4 & 0.67 & 53.3 & 0.0 \\
\hline 20 & Product lifecycle & 3.55 & 3 & 0.75 & 50.0 & 5.6 \\
\hline 21 & Measuring & 3.32 & 3 & 0.77 & 36.7 & 2.5 \\
\hline 22 & Standards & 3.31 & 3 & 0.69 & 36.7 & 2.3 \\
\hline 23 & Application of science & 3.28 & 3 & 0.86 & 40.0 & 1.8 \\
\hline 24 & Efficiency & 3.23 & 3 & 0.72 & 33.3 & 1.6 \\
\hline 25 & Heuristics & 3.04 & 3 & 0.76 & 30.0 & 4.2 \\
\hline 26 & Quality assurance & 2.97 & 3 & 0.61 & 16.7 & 3.8 \\
\hline 27 & Modularity & 2.87 & 3 & 0.90 & 13.3 & 3.4 \\
\hline 28 & Working principle & 2.82 & 3 & 0.89 & 16.7 & 4.5 \\
\hline 29 & Algorithms & 2.80 & 3 & 0.85 & 13.3 & 2.5 \\
\hline 30 & Complexity & 2.72 & 3 & 0.75 & 13.3 & 2.8 \\
\hline 31 & Intellectual property & 2.66 & 3 & 0.67 & 10.0 & 1.6 \\
\hline 32 & Tolerance & 2.49 & 3 & 0.64 & 3.3 & 11.0 \\
\hline 33 & Practical reasoning & 2.49 & 2 & 0.69 & 6.7 & 14.0 \\
\hline 34 & Technological trajectory & 2.38 & 2 & 0.59 & 0.0 & 6.0 \\
\hline
\end{tabular}


Table 3 Statistics for the list of contexts

\begin{tabular}{|c|c|c|c|c|c|c|}
\hline Rank & Possible context & Mean & Mode & SD & $\begin{array}{l}\% \text { rating } \\
\text { with } 4 \text { or } 5\end{array}$ & Stability \\
\hline 1 & Energy in society & 4.37 & 4.00 & 0.72 & 93.3 & 3.7 \\
\hline 2 & Biotechnology & 4.27 & 4.00 & 0.69 & 93.3 & 5.0 \\
\hline 3 & Sustainable technology & 4.23 & 4.00 & 0.63 & 90.0 & 4.7 \\
\hline 4 & Transportation (using vehicles, traveling) & 4.14 & 4.00 & 0.62 & 86.7 & 0.1 \\
\hline 5 & Medical technologies & 4.10 & 4.00 & 0.92 & 86.7 & 1.1 \\
\hline 6 & Food & 3.94 & 4.00 & 0.58 & 80.0 & 3.8 \\
\hline 7 & Industrial production & 3.85 & 4.00 & 0.74 & 66.7 & 6.4 \\
\hline 8 & Water resource management & 3.84 & 4.00 & 0.79 & 73.3 & 3.9 \\
\hline 9 & Construction & 3.74 & 4.00 & 0.72 & 66.7 & 0.4 \\
\hline 10 & 2-way communication & 3.68 & 4.00 & 0.80 & 70.0 & 4.0 \\
\hline 11 & Global warming & 3.62 & 4.00 & 0.97 & 55.2 & 3.8 \\
\hline 12 & Domestic technologies & 3.60 & 4.00 & 0.79 & 58.6 & 5.4 \\
\hline 13 & Safety/security & 3.52 & 3.00 & 0.65 & 46.7 & 1.9 \\
\hline 14 & Nanotechnology & 3.48 & 4.00 & 0.91 & 50.0 & 1.0 \\
\hline 15 & Scientific research and exploration & 3.31 & 3.00 & 0.90 & 36.7 & 2.8 \\
\hline 16 & Security/big brother & 3.04 & 3.00 & 1.00 & 33.3 & 1.1 \\
\hline 17 & Sports and recreation & 3.01 & 3.00 & 0.86 & 30.0 & 0.9 \\
\hline 18 & 1-way communication & 2.97 & 3.00 & 0.82 & 20.0 & 2.3 \\
\hline 19 & Virtual reality & 2.96 & 3.00 & 0.88 & 20.0 & 4.7 \\
\hline 20 & Imagining the future & 2.90 & 3.00 & 0.88 & 26.7 & 4.5 \\
\hline 21 & Do-it-yourself & 2.70 & 3.00 & 0.92 & 16.7 & 8.0 \\
\hline 22 & Politics and technology & 2.66 & 3.00 & 0.93 & 16.7 & 5.0 \\
\hline 23 & Rescue & 2.62 & 3.00 & 0.69 & 0.0 & 9.0 \\
\hline 24 & Packaging & 2.58 & 3.00 & 0.87 & 10.3 & 6.7 \\
\hline 25 & Toys & 2.56 & 3.00 & 0.86 & 13.3 & 13.0 \\
\hline 26 & Robotization of society & 2.55 & 2.00 & 0.82 & 10.3 & 10.8 \\
\hline 27 & Technology for peace & 2.50 & 3.00 & 0.90 & 6.7 & 15.9 \\
\hline 28 & Music & 2.50 & 2.00 & 0.90 & 10.0 & 17.4 \\
\hline 29 & Entertainment & 2.46 & 3.00 & 0.90 & 6.7 & 18.9 \\
\hline 30 & Education & 2.44 & 2.00 & 0.66 & 3.3 & 2.0 \\
\hline 31 & Personal care & 2.42 & 2.00 & 0.74 & 6.7 & 9.1 \\
\hline 32 & Digital photography & 2.38 & 3.00 & 0.74 & 3.3 & 8.8 \\
\hline 33 & Art and technology & 2.36 & 3.00 & 0.88 & 6.7 & 2.1 \\
\hline 34 & Crime scene investigation & 2.29 & 3.00 & 0.76 & 0.0 & 18.9 \\
\hline 35 & Religions \& technology & 1.59 & 1.00 & 0.72 & 3.3 & 14.6 \\
\hline
\end{tabular}

Literature does not provide unambiguous cut-off points for consensus (indicated by the SD) and stability (calculated as 100 times "new score minus old score" divided by "new score"). As a measure for consensus, for several authors a standard deviation below 1 already signifies consensus. Osborne et al. used the stricter criterion that $66 \%$ of respondents should rate the context 4 or above. Osborne et al. (2003) also used 33\% as the maximum for stability (higher percentages mean: no stability). That requirement is easily met in our scores, both for concepts and contexts. 
The results of the Delphi study have shown that a number of concepts stand out as possible foundations for an engineering and technology education curriculum.

The concepts "design (as a verb)," "system," "modeling," "social interaction," and "optimization" were given the highest average score by the Delphi experts. Of these, "optimization" gave rise to somewhat more disagreement among the experts than did the other concepts in this top-five list.

"Second-best" concepts were "innovation," "specifications," "design (as a noun)," "sustainability," “energy," "materials," "resource," "trade-offs," "technology assessment," and "invention." Of these ten, "trade-offs,", "technology assessment," and "invention" had somewhat less consensus than the other seven.

The concept "function" made an important change from round two to round three. In round three it receives a significantly lower percentage of 4 and 5 ratings. It dropped from $67 \%$ in round two to $58 \%$ in round three, thus not making the criterion for top concept in the final round. This is combined with a lower standard deviation in round three. As our criterion is a flexible one, we considered including this concept in the final list of "most important concepts".

All this is followed by a whole list of concepts that get low average scores and high standard deviations. These concepts are apparently at least problematic. At the bottom of the list we find the concepts "technological trajectory," "practical reasoning," "tolerance," "intellectual property," "complexity," "algorithms," "working principle," "modularity," and "quality assurance." For two of these, namely "working principle" and "modularity," there was substantial lack of consensus. Several experts took the trouble to deviate from the round two average score and account for the deviation. In their opinion these concepts were more important than suggested by the average score. Less disagreement existed about rejecting "practical reasoning," "complexity," and "algorithms." But here too we find experts defending a higher score. One of the experts suggested that the concept "practical reasoning" is very important but could be a sub-concept of "design (as a verb)." Similarly, another expert suggested that "complexity" could belong with "systems." A third expert suggested that "modularity" could also be put under "systems." These suggestions seem worth considering. The remaining concepts with low scores (below 3) were rejected by agreement.

Compared to the fairly good agreement on the concepts, it is striking that the contexts gave more rise to disagreement. Standard deviations were generally higher here $(0.80$ on average) compared to the concepts ( 0.70 on average). But let us start with what was clearly agreed upon. The contexts "energy in society," "biotechnology," "sustainable technology," "transportation" and "medical technologies" stand out as useful. Of these, "medical technologies" gave rise to the most disagreement. One expert explained that he scored it lower because these technologies seem to draw students to medical schools rather than engineering programs. The context "nanotechnology" scores a mode of four but gives rise to much disagreement. Proponents state that as an emergent technology that has big consequences for our future it is a very important context. Others view it as rather inaccessible and doubt its suitability for teaching technology to young learners. One expert also remarks that this context is much more about science than about technology. Next are "food," "industrial production," "water resource management," "construction," "twoway communication," "global warming," and "domestic technologies." Of these, "global warming" gives rise to more disagreement; some experts suggest it is close to, and should be integrated with, "sustainable technologies." Rejected with agreement were the contexts "religions and technology," "crime scene investigation," "art and technology," "digital photography," "personal care," and "education." The experts found most of these too 
narrow and suggested that they could be subsumed under one of the other contexts. The exception was "religions and technology," which seems difficult to turn into practical material. Also, it may put the teacher in a difficult position as it can be a loaded subject. For the contexts "entertainment," "digital photography," "art and technology" and "religion and technology," there are nevertheless one or two enthusiastic supporters with arguments for their position. One interesting defense for the last two is that boundary crossing provides rich contexts. Several experts argued to include "digital photography" under "communication" or as a form of "art and technology" under "entertainment." Entertainment is defended as most relevant as it is so much part of the social, emotional, and physical well-being of students (influencing them both positively and negatively). The remaining contexts got only average scores (2.5-3.5) and often a lack of agreement. Highest standard deviations amongst these were found for "scientific research and exploration," "politics and technology," "security/big brother," "music," and "technology for peace." Several experts commented that they ranked "do-it-yourself" higher than the round two average because this context was the route to engineering for many students.

It is striking that the traditional domains of application in the US remain popular, as we see "transportation," "communication," "production," and "construction" all in the list of highly scoring contexts. One of the experts expressed concern about this and wondered if there is a need to take a step forward. Biotechnology was already fairly popular in US technology education curricula and it features strongly here. Perhaps the most interesting outcome is that some new contexts stand out: "energy in society," "sustainable technology" (with overwhelming support) and "global warming" (with less agreement). These seem to be related to an awareness of the global importance of these contexts. This is reflected by what one of the experts wrote, who could see "making the world a better place" as the umbrella context. Several experts suggested combining the three contexts, and they see global warming as a sub-context or discussion item within these or other contexts. Apart from this, most remarks highly favor the subject.

"Food" is highly supported by $80 \%$ of respondents, for different reasons: it touches upon current societal problems on world scale, is heavily influenced by technology and is a basic human need (so familiar to all of us).

Though it gets a lower average rating and higher standard deviation, "water resource management" is highly praised in the comments. Different experts appreciate this context and used similar arguments as those used for food: it is increasingly becoming an issue of high societal relevance, is heavily influenced by technology, and is a basic human need. A single expert commented that it is too narrow. This is probably the reason for the lower ratings. At the same time another expert is taken in by the broadness of it: "from potable water and desalinization to river and flooding control to reservoir building to bottled water to..."

"Medical technology" is another definite winner. "Domestic technologies" gets 4+ from little over half of the respondents (with remarks as "especially automation" and "part of student's life") but with much less strong agreement.

Another expert observed that the more practical contexts of lower abstraction level did not survive, in spite of the fact that these are strongly promoted by current educational research. Traditions seem to be strong among the experts.

\section{General issues raised}

Some remarks made by the experts give rise to more general considerations. In the first place, there is the issue of the level of abstraction, both in the concepts and in the contexts. 
Several experts remarked that the Delphi study would result in a list of separate concepts, while actually the list should be structured. Some concepts are at a higher level of abstraction and generality than others. Also there are numerous connections between the concepts that remain hidden in the list. This is clearly one of the limitations of this Delphi study, and it probably could not be avoided, given the limitations of the Delphi method. One could argue that bringing structure to the list is a necessary next step in the process of developing a curriculum. One way of doing this can be to draw a concept map that contains all of the concepts identified by the experts as important. The map should also feature the sub-concepts. The experts saw some of the sub-concepts as important but ranked them low because of their low level in the hierarchy of abstraction. The same problem arises in the list of contexts. Several contexts were seen as very important by the experts but were ranked low because of their specificity.

Another issue for the debate is what to do with the recent insight in educational research that says that contexts should be practices in which students can be involved. That idea clearly was not a priority in the experts' considerations. Is this a matter of traditionalism or a lack of awareness of the latest educational research studies? Or did the experts consciously reject this new idea, preferring instead the more traditional, broader contexts? Several experts mentioned that the broad and general contexts should be read as umbrella terms that need further concretization and operationalization. In defense of the broader contexts, several experts remarked that in their view engineering and technology education should involve students in the wider global challenges, and this opinion seems to be a valid consideration.

A third issue that several experts noted was whether or not the concepts should be specific for engineering and technology. Sometimes experts remarked that they rejected a concept because it was not specific for engineering and technology. How should we value that consideration? Would it lead to the immediate rejection of one of the highest scoring concepts, "systems," because it emerged not in engineering but in biology, and is used in many disciplines other than engineering and technology? Why then was this criterion of uniqueness (for engineering and technology) not applied more consistently? Were relevant concepts lost not because they were less important but because they were less specific for engineering and technology? How do we value that? These are questions that were considered in the later expert panel meeting.

A fourth issue concerns the term "engineering and technology." Some experts suggested that engineering and technology are different and cannot be taken together in one expression that suggests they are almost the same. This raises the question, would separating the two have resulted in two different lists of concepts? If so, how would that be valued? To what extent is this remark related to the perceived difference between general and vocational education, which may suggest that engineering is for the latter and technology for the former? A related remark is that according to some experts the list of concepts was too focused on the design process and did not do justice to the social aspects of technology. Does that suggest a vocational bias in the list? In the list of preferred concepts, this fortunately does not seem to be a problem, because several concepts in this list are directly related to the social aspects of technology. The argument though is: all technologies exist only with human praxis. Therefore, this relationship needs to be embedded in each concept and not treated as something distinct to be considered separately. Looking at the list, we see that the concepts "design (as a verb)," "social interaction," and "technology assessment" seem to have the human-technology relationship embedded most clearly. Should all concepts clearly reflect the human-technology 
relationship? These questions, too, were discussed at the expert panel meeting following the Delphi study.

A fifth issue is the relationship between concepts and contexts. Some experts remarked that they had difficulty separating the two. The choice of contexts, according to them, cannot be independent from the preferences for certain concepts. Contexts are not infinitely flexible. Some are more suitable for learning certain concepts than others. The setup of the Delphi rounds did not take that into account. Here too we see a necessary next step in the process leading towards curriculum development.

A sixth issue concerns the different approaches taken by experts in evaluating the contexts and the request for an overarching "umbrella context". The proposals for new contexts and the comments on existing ones reveal that respondents take very different approaches in suggesting and evaluating contexts. Analyzing the comments, the proposed contexts and the general remarks on the context part, we find roughly nine approaches, each with a different view on what the main criteria for suitable contexts should be. In random order, they state the following:

"The contexts should...":

1. Be truly relevant to students' lives

2. Exemplify enduring human concerns, being fundamental to human nature and relevant in a variety of cultures and societies

3. Be situated around societal issues/problems

4. Encompass the Human-Made World

5. Be big examples, like the development of the paper clip, as described by Petroski

6. Be local (culturally, geographically)

7. Cover the technological domains

8. Use the "Designed World Standards" in "Standards for Technological Literacy"

9. Best fit three considerations:

(a) fit to the concepts;

(b) familiarity to the learner;

(c) ability for the instructor or curriculum designer to provide more and less complex versions of the contexts that help make salient the critical feathers and relationships.

One respondent noted that before trying to find a set of contexts, we need an overarching "supercontext" or "umbrella context" to work within. "Purpose" could be such an umbrella context. Almost all the approaches listed above could be viewed as overarching umbrella contexts and used to frame the search for a set of suitable contexts. Only the approach that the contexts must be local might be hard to use to this purpose. Is there a best approach, or can the approaches be combined? It seems that two types of contexts received high averages in the final round: the traditional contexts and contexts that fit the suitability criteria of a combination of approaches. An example of such a context is the high scoring "food." This context is suitable from each of the viewpoints of the first three types of approaches. In the expert panel meeting we have made an effort to find a combination of different approaches.

Finally, several respondents, from the Philosophy, History and Communication as well as from the Technology Education groups posed fervent appeals for a more central place for normative aspects in technology education. Issues relating to ethics, sustainability, and the relationship between humans and technology should be factored into (all) the concepts. Contexts should be used as a discussion arena for these normative issues. In round one a 
concept was suggested that we did not include in the new list but that is related to this: "unintended or unanticipated consequences": The idea that all technologies have consequences that are not anticipated by the designers. These consequences may be positive or negative. It seems this is a notion that is still lacking. One of the other respondents added: "Many (most?) of the great challenges on our planet in the 21st century (global warming, world hunger, pandemics, nuclear warfare, etc.) have resulted from technological endeavor and/or will be addressed by technological 'fixes.' ... I think it's far more important that kids understand that all technologies have unintended consequences and that we MUST assess them in that light (as well as for intended consequences)." On the other hand, a respondent warns: "Teachers shouldn't put themselves in the position of seeming to push a political agenda, so sensitive topics must be handled carefully. Some of the contexts could be very tricky to handle (like religion, politics, and technology for peace)." Also one respondent remarked that some of the concepts are too value laden ("robotization of society" and "security/big brother is watching you") and should be more neutral. The question here seems to be how neutral and "technical" technology education should or can be. Can or should we teach the nature of engineering and technology without involving normative aspects? In the panel meeting this issue has been discussed and a proposal was made that does justice to the appeal to give values a visible place in the lists of concepts and contexts.

\section{Second phase: panel meeting}

\section{Set-up}

The outcomes of the Delphi study have been used as the input for a meeting of a panel of experts, with the purpose of turning these outcomes into a framework for curriculum development. The panel consisted of five participants of the Delphi study (all from technology education) plus two other experts that had not been involved in the Delphi study (one from technology education and one from engineering education). Thus we created the possibility for a fresh look on the outcomes, while at the same time allowing input from those that were involved in the Delphi study preventing that the panel meeting would not do full justice to the Delphi study. Also two of the researchers were present (one of which has a background in both technology education and in the philosophy and history of technology). The process was as follows: first, the group reflected on the contexts that came out of the Delphi study; and second, reflected on the overarching concepts. Both of the lists were found to lack structure and hierarchy, which is understandable from the methodology of the Delphi study. An analysis was made of the nature of the consecutively ranked concepts and contexts to provide the necessary structure for use as a curriculum framework.

\section{Outcomes of the panel meeting}

The contexts that ranked high on the list that resulted from the Delphi study appeared to consist of two sub-groups of contexts. In the first place, the panel recognized the contexts that traditionally had been used in the US as curriculum organizers: construction, production, transportation, communication, and biotechnology. The remaining contexts all seemed to reflect major global concerns. Some examples of these are: energy, food, water, and medical technologies. This impression was confirmed by the motivations given by 
some of the experts in the Delphi, one of whom phrased this as "making the world a better place." In the discussion, the panel realized that both the traditional and the global concern contexts were related to basic human needs that are addressed by engineering and technology.

Thus, the panel developed a single list of contexts that reflected engineering and technological endeavors in the "umbrella contexts" of addressing personal, societal, and global concerns. This list includes the following: food, shelter (our translation of the context that was originally called 'Construction'), water, energy, mobility (originally called 'Transportation'), production, health (the former 'Medical technologies' context), security, and communication. The list is presented in Table 4.

This list both does justice to the outcomes of the Delphi study (it covers the top nine of the contexts list) and has a logic to support it (they are all basic human concerns). Another consideration was that the list would need to do justice to the fact that some of these contexts were put forward by the Delphi experts from a 'global concern' point of view, but other contexts originally were put forward because they allowed for deriving more concrete practices that would appeal to the learners because of their daily life character. So the panel decided to add the recommendation that when developing a curriculum, the contexts should be elaborated in two directions: in a 'personal concern' (or 'daily life practice') direction and in a 'global concern' direction.

The next step was to reflect on the concept list. It was evident that this list contained concepts of different levels of abstraction. Therefore it was decided to identify those concepts with the highest level of abstraction and to put the remaining concepts under these 'main' concepts as much as possible. Starting from the top of the list, the panel identified the following five concepts as the most abstract: design (as a verb), systems, modeling, resources, and values. The last-mentioned concept did not feature as such on the list but was introduced by the panel as a heading for several concepts in the list that were valuerelated. This introduction also answered to the concern of a number of Delphi experts to make the normative dimension of technology and engineering visible in the list of concepts. The remaining concepts could then be put under these five main headings as subconcepts, but here the panel realized that there is no sound basis for drawing the line between those concepts that were included as sub-concepts and those that were not. In fact, all concepts on the list (except for two) were given at least a score of ' 3 ', which indicates that even though not all were considered equally important, nearly all concepts were seen as fairly relevant. It would therefore be a missed opportunity for innovation of the curriculum to leave out concepts based on an arbitrary decision about where to draw the line.

Table 4 Contexts

\begin{tabular}{l}
\hline Context \\
\hline Shelter ('construction') \\
Artefacts for practical purposes ('production'/'manufacturing') \\
Mobility ('transportation') \\
Communication \\
Health ('biomedical technologies') \\
Food \\
Water \\
Energy \\
Safety
\end{tabular}


The panel decided to include the concepts that ranked high on the Delphi list. They serve as examples of sub-concepts that have a certain status of priority because they were ranked highly by the Delphi experts. Thus the panel ended with the list of concepts and subconcepts that is presented in Table 5.

Finally the panel decided to put forward a number of remarks concerning a possible next step, namely developing these lists into an ontology-based curriculum. In the first place, the panel noted that there are two possibilities of structuring the curriculum: according to the concepts, or according to the contexts. The first option will result in modules like 'Systems', 'Resources' or 'Values' and can be used to teach and learn the concepts in the way that is suggested by the current ideas on concept-contexts learning (learning a concept in a series of different contexts, which gradually leads to an insight on a more abstract level, and thereby also transferability to new contexts). This can be called a 'systematic' or 'disciplinary' approach. It would be similar to the "Man-Made World" course book that we had used as a source of inspiration for identifying possible concepts. The second option results in modules like 'Water', 'Energy', or 'Mobility' and can be used to show the versatile nature of the concepts because these will all feature in the module. This can be called a 'thematic' approach and currently seems to be the most popular internationally. Both options are justifiable and a curriculum could even contain a combination of modules based on both options. A second remark is that before developing the curriculum it is necessary to investigate the specific meaning concepts get when they are applied to the different contexts. This is necessary, because current theory on situated cognition (Hennessy 1993) claims that the concepts are indeed 'colored' by contexts and are therefore context-dependent to a certain degree. A third remark was that it would be useful for curriculum developers to have case studies or vignettes that illustrate how the framework of concept and context lists can be developed into a curriculum. A fourth remark was that the framework does not yet reflect the need to develop both qualitative and quantitative activities when developing the curriculum. Current technology education

Table 5 Concept list

\begin{tabular}{ll}
\hline Main concept & Sub-concepts \\
\hline Designing ('design as a verb') & Optimising \\
& Trade-offs \\
& Specifications \\
& Invention \\
& Product lifecycle \\
& Artefacts ('design as a noun') \\
Systems & Structure \\
& Function \\
Modelling & Materials \\
Resources & Energy \\
& Information \\
Values & Sustainability \\
& Innovation \\
& Risk/failure \\
& Social interaction \\
& Technology assessment \\
& \\
&
\end{tabular}


curricula are often biased towards the qualitative (only conceptual, without calculations), but the engineering dimension requires serious attention for the quantitative also.

After the session, the panel felt that justice was done to the outcomes of the Delphi study, while at the same time the result now was more systematic and structured. The group decided to start developing project proposals in which the framework is elaborated and transformed into a curriculum proposal.

\section{Conclusions and recommendations}

Our Delphi study and expert panel meeting have resulted in a list of concepts and a list of contexts that can be used for developing engineering and technology education curricula. The approach of teaching concepts in contexts is a middle road between total unbelief in the possibility of teaching and learning abstract concepts that can be applied in different contexts and a naive belief in the possibility to teach such concepts directly at a high level of abstraction only to apply them later in various contexts. In the concept-context approach even the use of the term 'transfer' is used with some hesitation because teaching a concept in one context and then immediately transferring that concept to another context is problematic. The idea is that by teaching concepts in a variety of contexts gradually the learner will start to recognize the more generic nature of the concepts and be able to apply it in new contexts. This recognition has to be supported carefully, as the concepts take different 'appearances' in different contexts. Although at a high level of abstraction both a building and a bike are artifacts, it is by no means evident to novices in the field that this is the case. Evidently an 'artifact' in the context of shelter has a different 'appearance' than in the context of transportation. Yet, there is value in seeing the connection between both. This helps the learner to get a better understanding of the nature of both the building and the car. Similar examples can be provided for the other concepts and contexts in our results. We recommend that curriculum developers consider the use of our lists of concepts and contexts to rethink the engineering and technology education frameworks and curricula. These lists may help, for instance, to bring more conceptual coherence in the now very extensive list of Standards for Technological Literacy that was developed and is now implemented in the USA. The current New Zealand curriculum is another example of an approach in which concepts and contexts play a vital role, and perhaps for a next revision of this curriculum, too, the outcomes of our study can be useful.

Open Access This article is distributed under the terms of the Creative Commons Attribution Noncommercial License which permits any noncommercial use, distribution, and reproduction in any medium, provided the original author(s) and source are credited.

\section{References}

Brown, B. B. (1968). Delphi process: A methodology used for the elicitation of opinions of experts. Document No: P-3925. Santa Monica, CA: The RAND Corporation.

Childress, V. W., \& Rhodes, C. (2008). Engineering outcomes for grades 9-12. The Technology Teacher, 67(7), 5-12.

David, E. E., Jr, Piel, E. J., \& Truxall, J. G. (1971). The Man-made world. New York: McGraw-Hill Book Company.

de Vries, M. J. (2005). Teaching about technology. An introduction to the philosophy of technology for nonphilosophers. Dordrecht: Springer. 
Dearing, B. M., \& Daugherty, M. K. (2004). Delivering engineering content in technology education. The Technology Teacher, 64(3), 8-11.

Hennessy, S. (1993). Situated cognition and cognitive apprenticeship: implications for classroom learning. Studies in Science Education, 22, 1-41.

International Technology Education Association. (2000). Standards of technological literacy. Content for the study of technology. Reston, VA: ITEA/Technology for all Americans project.

Osborne, J., Ratcliffe, M., Collins, S., Millar, R., \& Duschl, R. (2003). What ideas about science should be taught in school science? A delphi study of the 'expert' community. Journal of research in science teaching, 40(7), 692-720.

Pilot, A., \& Bulte, A. M. W. (2006). The use of contexts as a challenge for the chemistry curriculum: Its successes and the need for further development and understanding. International Journal of Science Education, 28(9), 1087-1112.

Reeves, G., \& Jauch, L. R. (1978). Curriculum development through Delphi. Research in Higher Education, $8(2), 157-168$.

Westra, R., Boersma, K., Waarlo, A. J., \& Savelsbergh, E. (2007). Learning and teaching about ecosystems: Systems thinking and modelling in an authentic practice. In R. Pintó \& D. Couso (Eds.), Contributions from science education research (pp. 361-374). Dordrecht: Springer. 